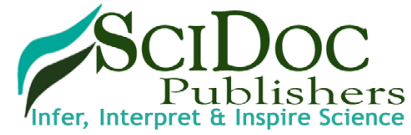

\author{
International Journal of Clinical Therapeutics and Diagnosis (IJCTD) \\ ISSN: 2332-2926
}

\title{
UFPel CuidATIVA Unit: \\ A Palliative Care Concept in Tune with Practice
}

Research Article

Carriconde Fripp J* ${ }^{*}$, Oliveira Thomaz $\mathrm{F}^{2}$, Medeiros Amaral AL², Avila Amaral R 3 , Sanghi $\mathrm{S}^{4}$

${ }^{1}$ CuidATIVA Unit, Department of Medical Clinic, School of Medicine, Federal University of Pelotas, Pelotas, RS, Brazil.

${ }^{2}$ CuidATIVA Unit, Brazil.

${ }^{3}$ CuidATIVA Unit, Graduate Program in Environmental Education, Federal University of Rio Grande, Brazil.

${ }^{4}$ CuidATIVA Unit, Social worker, School Hospital - EBSERH, Federal University of Pelotas, Pelotas, RS, Brazil.

Abstract

The article aims to reflect on the implementation of CuidATIVA, the Day Palliative Care Unit of the Federal University of Pelotas, in the state of Rio Grande do Sul, Brazil. It analyzes its structure and history that involves collaborative creative processes to make it a reality, based on people's autonomy, active participation, solidarity and group self-management. The main focus of this analysis is on the process of experimenting with new ways of caring and promoting health, combining popular and scientific knowledge and generating quality of life by creating a concept of Palliative Care open to community participation and the unforeseen circumstances of the implementation process itself. This is an article in which the authors act in the process of construction of Palliative Care scenarios at CuidATIVA, involving linearities and continuities, also discontinuities, folds, indentations, interruptions and bifurcations, perfect rhizome image, a concept of botany applied to the philosophy of difference (Deleuze and Guattari) and to the ecology of knowledge (Boaventura de Souza Santos), a possibility of ethical-aesthetic-political resistance. Community participation and purposeful political articulation stand out in CuidATIVA, focusing on sustainability in order to promote the participants' quality of life, aiming to minimize physical, emotional, social and spiritual problems, including practices aimed at caregivers, family members and the team work itself.

Keywords: Palliative Care; Total Pain; Integrative and Complementary Practices (Práticas Integrativas E Complementares, Pics); Functional Rehabilitation; Day Care; Rhizome; Philosophy of Difference; Ecology Of Knowledge.

Since 2005, the Federal University of Pelotas/UFPel has a vocation in the area of palliative care, when at the time it was implemented at the UFPel School Hospital, via the University Support Foundation (Fundação de Apoio Universitário, FAU), the Interdisciplinary Home Hospitalization Program (Programa de Internação Domiciliar Interdisciplinar, PIDI), structured with a multi-professional team to treat symptoms and alleviate suffering of people with advanced cancer, through a Singular Therapeutic Project with interdisciplinary strategy.

Palliative Care consists of assisting people with severe chronic diseases to improve their quality of life by controlling pain and all symptoms of a physical, emotional, social and spiritual nature. This kind of care does not end the person's death, but continues to accompany the family. The term Palliative comes from the Latin Pallium, as the protective cloak of storm warriors was called. The
World Health Organization (WHO) defined the concept in 2002 and published the Palliative Care Handbook in 2007.

The World Health Organization defines Palliative Care as a strategy that improves the quality of life of patients, caregivers and their families, and should be made available as early as possible in the presence of life-threatening disease-related problems. It advocates for the prevention and alleviation of rigorous biopsychosocial and spiritual suffering, extending it to the grief phase.

UFPel's CuidATIVA Unit, located at 104 Duque de Caxias Avenue (Antiga Laneira), Fragata District, City of Pelotas, state of Rio Grande do Sul /Brazil, was designed in 2015 and has been progressively implemented since 2016 with specialized care in Palliative Care.

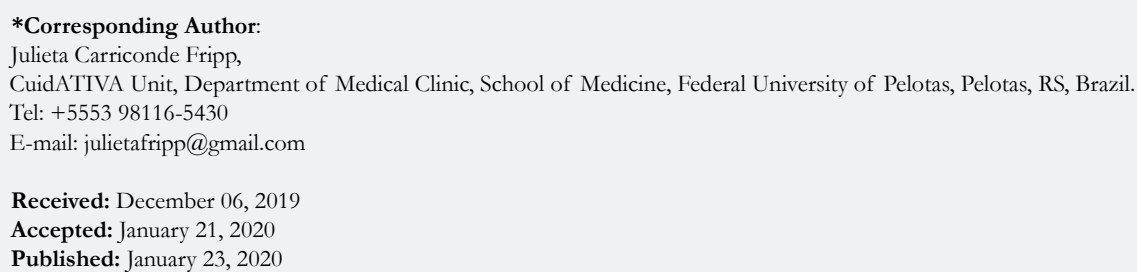

Copyright: Carriconde Fripp $\mathrm{J}^{\circ}$ 2020. This is an open-access article distributed under the terms of the Creative Commons Attribution License, which permits unrestricted use, distribution and reproduction in any medium, provided the original author and source are credited. 
The purpose of this article is to reflect on the implementation process of CuidATIVA and its evolution, focusing on the accomplished initiatives and take the first steps in the theoretical elaboration of a concept of health in the area of Palliative Care from the analysis of this process. We present the history and structure of CuidATIVA (Figure 1), as well as the collaborative creative processes developed in order to make it a reality, involving people's autonomy, active participation, solidarity and group selfmanagement. Palliative Care is a concept inspired by the palliative care of physician Cicely Saunders, based on the philosophy of Gilles Deleuze and Félix Guattari, in particular on the rhizome conception they import from botany, as well as Edgar Morin's theory of complexity.

Thus, the CuidATIVA Unit (Day Care) 100\% SUS is an innovative space in the area of Palliative Care, which includes Integrative and Complementary Practices (PICs), Functional Rehabilitation (physical education, occupational therapy and physiotherapy), Ambulatory Care (multi-professional) and Embassy (host in waiting room and art therapy - Figure 2), involving volunteering and professionals. In addition to sick people, their caregiver and family members count on CuidATIVA services.
Our actions continually dialog with our reflections and the dynamic interactions between theory and practice have emerged a concept of palliative care, which we began to elaborate from the historical records and theoretical references that inspire the evolution of the UFPel CuidATIVA Unit, written from the point of view of four researchers working on the implementation of the CuidATIVA Unit. It is the result of an intervention articulated by a rhizomatic way of thinking and acting, expressing a plural knowledge that emerges from human diversity and a network of relationships that has been articulated in order to make CuidATIVA a reality. The professionals and practices developed in this Palliative Care environment manifest the construction of a complex and unique knowledge.

In the CuidATIVA Unit, activities are performed by professionals from different areas (technicians, teachers and volunteers) and students, adding various knowledge that interact with each other in order to improve quality of life. It also involves traditional therapies and environmentally sustainable integrative and complementary health practices (Figure 3). This work qualifies people's achievement level, improving physical, mental, social

Figure 1. Revitalization of the Sérgio Arouca Auditorium. CuidATIVA Collection Date: 2018.

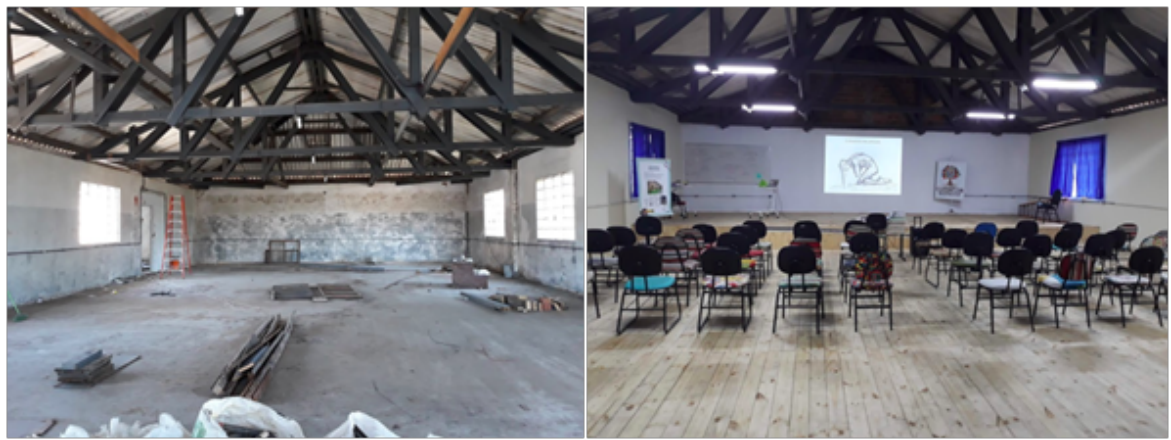

Figure 2. Art therapy. CuidATIVA Collection Date: 2017.

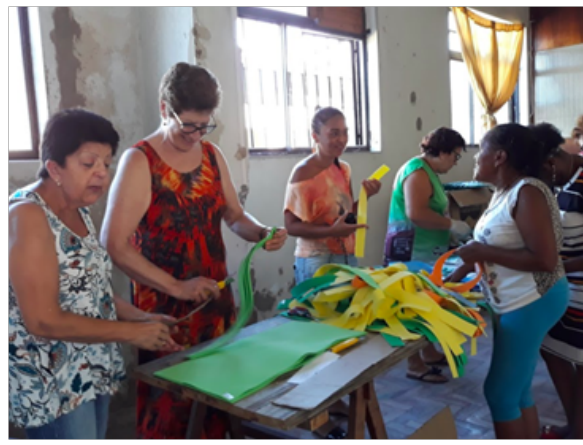

Figure 3. Phytotherapy Joint Effort. CuidATIVA Collection Date: 2018.

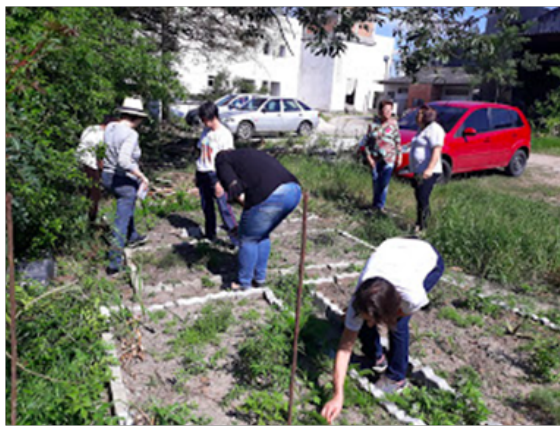

a. The Unified Health System (Sistema Único de Saúde, SUS) is one of the largest and most complex public health systems in the world, ranging from simple care for blood pressure assessment through Primary Care to organ transplantation, ensuring full, universal and free access for the country entire population. With its creation, the SUS provided universal access to the public health system without discrimination. Integral health care, not just care, has become a right of all Brazilians, from pregnancy and for life, focusing on health with quality of life, aiming at prevention and health promotion. Available in: http:// www.saude.gov.br/sistema-unico-de-saude\#n-que-e 
and spiritual well-being, enhancing autonomy and solidary social relations.

Actions in the CareATIVA Palliative Care service enhance the popular cultures valuing their knowledge and practices. The principles of the SUS (Universality, Equity and Integrality) are present in the daily life of CuidATIVA, added to the foundations of cooperation, sustainability and human emancipation.

In the municipality of Pelotas and cities in the southern region of Rio Grande do Sul, public health systems and services in general cannot provide enough and adequate resources to control symptoms associated with chronic diseases in network systems and in different health care points. Lack of information about Palliative Care generates prejudice from both health professionals and lay people, who sometimes believe that these services are only for those who are about to die. This leads to many situations of patients not having access or being welcomed in the health network, for example, when there is an initial diagnosis of cancer with no possibility of cure, as patients are referred only in extreme situations with a large symptom burden.

To reach the complexity of humanized care centered on the person in its uniqueness, there is a need to understand that all knowledge is peculiar, unique to each human being and their ethnic and sociocultural origin, with distinct traditions, habits and values, neither larger nor better, for all knowledge and doings have their own merits and reasons for existing. It includes health initiatives that make relationships between singular knowledge and bold enough to question, deconstruct and reconstruct practices and knowledge established by the academic tradition through the exchange between the scholar and the popular. In our practice, we are moving towards multi-, inter- and trans-disciplinary knowledge in order to develop a way of learning focused on good living and learning to learn (Figure 4), expanding the capacities of intellectual autonomy and human emancipation.

In addition to relieving symptoms in the Palliative Care Outpatient Clinic (Figure 5), through multi-professional care, the CuidATIVA Unit was also designed to redefine life histories and welcome of patients with chronic pathologies vocations and desires, in order to create an environment of expression of thoughts and feelings, involving more participation, interaction, dialog and improved quality of life, regardless of the time left to them. This is most evident in Art Therapy activities, Physical Rehabilitation processes, Encounter Groups (Mourners and Caregivers), Therapeutic Workshop and Interactive Theater Group, spreading into other Integrative and Complementary CuidATIVA Practices.

The inclusion of the universe of Integrative and Complementary Practices in the Palliative Care service meets the need to manage "Total Pain" (physical, emotional, social and spiritual). It allows to integrate activities that value the patients' world views and needs, generating more affection, friendship, happiness, individual and interpersonal harmonization, companionship, balance, fullness and meaning to life.

We understand that the Palliative Care concept, in line with the practice developed in CuidATIVA, is being formed daily and the result of the participation of the authors implicated in their daily practices, assuming an active and critical posture, often contradictory, involving reflecting, analyzing, make decisions, take responsibility, study, undertake alliances, gather data, ultimately affecting and being affected by the process. In this context, the authors' personal and professional universes interact in multiple dimensions, influencing each other. According to Ferrara (1999),

Figure 4. Pet Therapy. CuidATIVA Collection Date: 2019.

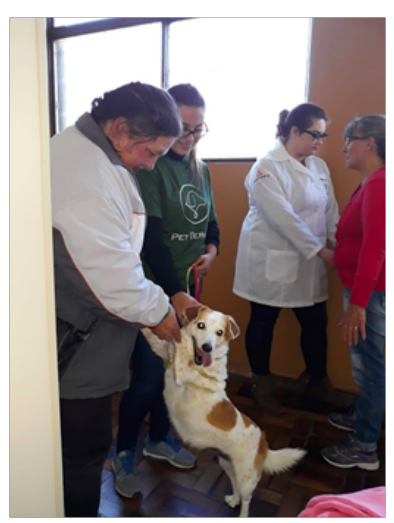

Figure 5. Outpatient Care. CuidATIVA Collection Date: 2018.

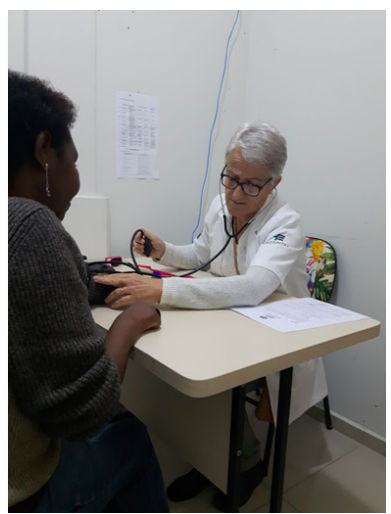


cultures are subjected to fundamental instabilities, which cannot be predicted or determined. The parameters of change are the only possibilities for analysis and interpretation.

The main focus of this analysis is on the process of experimenting with new ways of caring and promoting health, of living and relating, without imposing a new categorization, generating wellbeing and quality of life by creating, with a focus on practice, a concept of Palliative Care. The inconsistencies and unforeseen aspects of the implementation process of CuidATIVA are a collective action permeable to the new and to dialogu, welcoming knowledge and allowing the human to reinvent itself and transform the reality in which it is inserted. The conception herein developed comprises various meanings crystallized in the institutions, aiming to question them from a transformative sociopolitical understanding.

\begin{abstract}
A montage or device that produces innovations that generates events and series of transformations, updates virtualities and invents the new radical. In one device the goal to be achieved and the process it generates are immanent with each other. A device is composed of a semiotic and a pragmatic machine and integrates connecting heterogeneous elements and forces (multiplicities, singularities, intensities), which ignore the formally constituted limits of molar entities (strata, territories, institutes, etc.). The devices, generators of absolute difference, produce alternative and revolutionary realities that transform the considered of the real horizon, the possible and the impossible (BAREMBLITT, 2012, p. 147).
\end{abstract}

The field of analysis is political consisting of several agents and multiple power relations, unfolding into alliances, conflicts, dissensions, convergences, agreements, disputes, betrayals, ruptures, new pacts and partnerships. It is a Palliative Care concept sensitive to environmental movements, which includes linearities and continuities, but also discontinuities, folds, indentations, interruptions and bifurcations - perfect rhizome image - botany concept applied to the philosophy of difference (Deleuze and Guattari), a possibility of ethical-aestheticpolitical resistance. Rhizome is a lavish formation in developing, confusing, hiding, proliferating, facing, retreating, cutting back, reinventing, advancing again, remaking itself, in short, a kind of stem eager to exist transforming itself. Kare Kosik (1976) states that "reality changes because we produce reality from our cultural productions". It is the impetus of the collective that constitutes CuidATIVA!

The analysis is delimited by the possibilities that arise during the actions performed inside and outside the CuidATIVA, allowing us to elaborate a concept in line with the ideas that may or may not be realized. It constitutes a kind of adventure through unknown territories, due to its openness to the new and the unexpected, emphasizing the importance of learning to deal with unforeseen events, doubts, oscillations, disturbances and concerns.According to Boaventura de Souza Santos (1985), in this situation converge meanings and constellations of meaning coming, like rivers, from the springs of our local practices and dragging along the sands of our molecular, individual and community pathways.

It is a more spontaneous dimension. This beyond-the-borders is an unexplored or nonexistent territory, where we create possibilities for more fluid and less bureaucratized coexistence relationships and social interactions, by elaborating a concept of care aimed at a natural person with life-threatening chronic disease and no possibility of cure. A concept that does not take refuge in reflection, but operates and transforms, urging others to engage in the creative process through active participation and solidarity (Figure 6). Actions are orchestrated by a collective that affects and allows itself to be affected, together and from the group, in a health education process that extends the frontiers of humanized care, promoting relationships without affiliation, but making alliances, always intense, but not eternal and much less subservient.

This conception manifests the need to produce a thought that goes beyond the limits of Cartesian logic, a complex thought, finding solutions to everyday problems through a praxis and an ethics sensitive to the life and pain of the other, especially the most fragile. The social relations experienced in the process happen thanks to the existence of an environment that fosters the exchange between different world views, allowing the coexistence of various points of view (epistemological, aesthetic, political, philosophical, religious etc.) and the interaction between different ethnic groups, social classes, genders, age groups. These are modes of coexistence fostered by care when cultivating friendship relationships, companionship, solidarity and affection, reinventing caring, touching, seeing, feeling, hearing, speaking, affecting and being affected by the other suffering. From the perspective of Boaventura de Souza Santos (1985), knowledge is produced in different spaces, in relatively amethodical forms, constituted from a methodological plurality. Knowledge has a utopian and liberating dimension.

The concept of Palliative Care developed in CuidATIVA highlights the importance of learning to deal with the strengths and weaknesses of cooperative work, to creatively address injustices and oppressions, to feel and perceive life from other

Figure 6. Revitalization of the academic room. CuidATIVA Collection Date: 2018.

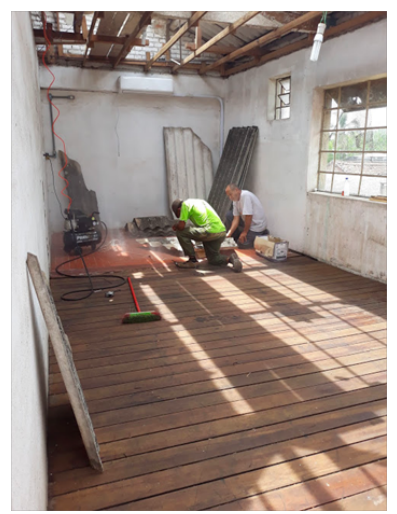


angles and perspectives. This allows people to feel the force of emotion, imagination and intuition, important dimensions in the elaboration of complex thinking. These are important moments, as they break with alienations, driving action and resistance, creating conditions of possibility for the human to manifest his sensitive, aesthetic, political and reality-transforming capacities. For Boaventura de Souza Santos (1985), changes occur in those who see themselves in what they see, analogous to a game. "The game presupposes a stage, the stage exercises with a text, the text is the author's autobiography. Game, stage, text or biography, the world is communication."

We are developing a concept much more inspired by nature and organic manifestation than in a social institution or organization, a concept that emerges from everyday practices, according to Amaral, Gentini and Amaral (2018, p. 12):

Unlike the methodologies centered on variable control, the practices developed favor uncontrollability and are open to the multiplication of variables and the proliferation of perspectives. Unlike the classical methods, weird variables are welcome. They are expected to interfere and generate waves of destabilization enhancing the invention of other ways of living, new ways of dealing with old human problems. It is a way of expressing ourselves with less self-censorship and of believing more in the complex collaborative processes of selfregulation of life and the human's ability to improvise.

The central element of the article concerns the process and not the results, requiring that ideas accompany the flow of activities developed in CuidATIVA, a process open to creativity and solidarity actions performed from a multi-professional and relational perspective, according to Castells (2000), where "the power of flows is more important than the flows of power".

In our experience, we understand that the dialog between science and non-disciplinary knowledge takes place in practice (Figure 7), being influenced by the direct or indirect participation of the community (mainly from those attending the CuidATIVA Unit, residents of the Fragata district, where it is located) and social movements (antimanicomial, environmental, agroecological, black, landless, union and student).According to Boaventura de Souza Santos (1985), the quality of knowledge is assessed by the personal satisfaction it will give to those who agree and share it. The aesthetic dimension of science approaches literary or artistic creation.In artistic creation the active dimension of the transformation of the real is subordinate to the contemplation of the result, the work of art.

The implementation of CuidATIVA is emerging as a possible alternative as science seeks a productive dialog with popular knowledge and knowledge arising from the art, philosophy, faith and culture of different peoples, by tracing a possible path towards future through the articulation of collaborative creative processes in a network. For Boaventura de Souza Santos (1985), knowledge is being elaborated on conditions of possibilities. These conditions of possibilities are being projected in the world from local space-times, where relationships and cultural habits are built.

Our understanding of health and teaching-learning spaces is based much more on our practices and reflections than on theories developed by other researchers. We invent and reinvent our own concept in productive dialog with researchers who, like us, engage in their research and are receptive to innovations and collaborative work. It is about being consistent with the actions developed and the values that guide the complex implementation process of CuidATIVA. Scientific knowledge will only be realized as such, to the extent that it becomes popular knowledge.

Considering the countless variables to meet the demands of CuidATIVA, which receives people with different physical, emotional, social and spiritual comorbidities and symptoms, outpatient elective consultations were organized with the support of a multidisciplinary team, undergraduates (curricular and optional medical interns, psychology, physiotherapy, social work, biology, veterinary medicine, occupational therapy and physical education) and volunteers from various areas, as follows (Table $1-3)$ :

In March 2018, the Functional Rehabilitation space was implemented, where professionals, teachers and students in the areas of Physical Therapy, Occupational Therapy and Physical Education, offer activities that improve autonomy and reduce the deleterious effects of diseases on patients' functional and cognitive abilities,in an area of 200 square meters that comprises three rooms for individual and collective attendance. It is worth noting that the qualification of this space, with regard to infrastructure, was made possible by planning and execution with voluntary labor. In addition, much of the available equipment (treadmills, exercise bikes, weight machines, stretchers, chairs, computers, and ultrasound equipment) was purchased through parliamentary amendment and community donations (Figure 8). The service operates daily in two shifts with about five hundred services per month.

An interinstitutional partnership was instituted with the Physical Therapy course of the Anhanguera College - Pelotas/RS, which allocated four teachers in functional rehabilitation activities and

Figure 7. Care Interdisciplinary Coffee. CuidATIVA Collection Date: 2019.

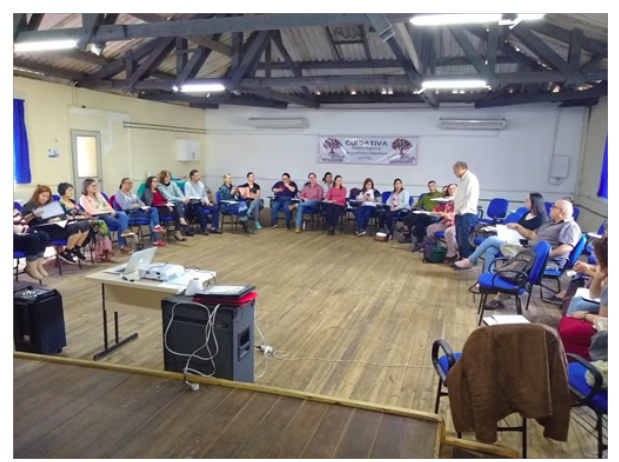


Table 1. Workers at the Hospital School/UFPel with employment relationship.

\begin{tabular}{|c|c|c|}
\hline Function & With exclusive dedication & With partial dedication \\
\hline Doctors & 1 & 2 \\
\hline Nurse & 1 & -- \\
\hline Social Worker & -- & 1 \\
\hline Physiotherapist & -- & 1 \\
\hline Psychologist & -- & 1 \\
\hline Dentist & -- & 1 \\
\hline Nursing technicians & 2 & -- \\
\hline
\end{tabular}

Table 2. UFPEL Professors in CuidATIVA Extension Projects (4 hours/week).

\begin{tabular}{|c|c|}
\hline Area & Number of people \\
\hline Medicine & 1 \\
\hline Occupational Therapy & 1 \\
\hline Music & 1 \\
\hline Nursing & 2 \\
\hline Biology (Therapeutic Gardens; Homeopathy; Medicinal Plants) $^{\mathrm{b}}$ & 3 \\
\hline Psychology & 2 \\
\hline Veterinary Medicine (Pet Therapy) $^{\mathrm{c}}$ & 1 \\
\hline Law (Care Law $^{\mathrm{d}}$ & 3 \\
\hline
\end{tabular}

Table 3. Volunteers in actions in the CuidATIVA Extension Project (4 hours/week).

\begin{tabular}{|c|c|c|}
\hline Performance area & Number of people & Action \\
\hline Physical Education & 3 & CuidATIVA Rehabilitation \\
\hline Psychology & 1 & Ambulatory Total Pain \\
\hline Nutrition & 1 & Ambulatory Total Pain \\
\hline Reiki $^{\mathrm{e}}$ & 2 & PIC \\
\hline Ayurveda ${ }^{\mathrm{f}}$ & 1 & PIC \\
\hline Aromatherapy ${ }^{\mathrm{g}}$ & 1 & PIC \\
\hline Circular Dance $^{\text {h }}$ & 1 & PIC \\
\hline Drama Group ${ }^{i}$ & 2 & PIC \\
\hline Caregivers Meeting Group & 1 & PIC \\
\hline Bereaved Meeting Group ${ }^{k}$ & 1 & PIC \\
\hline Art Therapy & 8 & PIC \\
\hline $\begin{array}{l}\text { Therapeutic Workshop (Integrative } \\
\text { Community Therapy) }\end{array}$ & 2 & PIC \\
\hline Acupuncture and Auriculotherapy & 1 & PIC \\
\hline Physiotherapy & 1 & CuidATIVA Rehabilitation \\
\hline
\end{tabular}

b. Therapeutic Gardens: Work performed in a collective environment and integrated with the inclusion of patients, families, volunteers, students and professionals with exchanges of popular and scientific knowledge for the production of organic products; Medicinal plants:Preparation of seasoned salt, syrup, medicinal soap, ointments, nasal serum, medicinal plants with analgesic effect, healing, among others, from the participants' demand.

c. Pet Therapy: Animal-assisted education and therapy as an adjunct to conventional health care methods, a complementary type of therapy that involves animals as a form of treatment.

d. Care Law: It aims to bring human rights closer to the right to decent health, to provide legal support inherent to palliative care and the termination of life, to support patients and families in the construction of Advance Will Directives and to promote the exercise of citizenship through access to justice.

Reiki: Practice of laying on of hands by touch or approach for channeling vital energy, which integrates actions to promote energy balance, health maintenance and rehabilitation and disease prevention. Ayurveda: Therapeutic approach of Indian origin, according to which the human body is composed of five elements - ether, air, fire, water and earth - which compose the organism, the energetic and emotional states and, in imbalance, can induce the emergence of diseases. It is directly related to integral care and biopsychosocial and spiritual balance.

Aromatherapy: Therapeutic practice that uses the properties of essential oils to restore body's balance and harmony to promote physical and mental health.

h. Circular Dance: It improves self-esteem, relieves physical, psychosocial and spiritual suffering. The circle, a universal symbol, provides the unity and harmonization of the group, which moves according to folk, traditional or popular dances of different origins.

"Interactive Theater Group: Drama and Therapy" Extension Project with drama workshops, conversation wheels and performing shows. It provides personal development experiences through relationships of mutual trust and the development of creative, expressive and communicative skills. The work of scenic construction is supportive, self-managed and inspired by patients' life histories.

mutual trust and the development of creative, expressive and communicative skills. The work of scenic construction is supportive, self-managed and inspired by patients life histories.
Caregivers Group: Offered by UFPel social workers. It qualifies patients and caregivers care, reducing overload, enabling greater integration and providing exchanges of different care experiences. Bereaved Group Offered by UFPel social workers and volunteer chaplain. One of the principles of palliative care concerns the provision of a support system to assist family members during the patient's illness and coping with grief in order to minimize feelings of sadness, loss, anger, guilt, loneliness and of abandonment.

1. Art therapy. This is one of the services of the CuidATIVA Embassy, a waiting room reception space. On-site, volunteers hold Art Therapy workshops Monday through Friday, open to users. The activities include sewing, knitting, yo-yo, painting, art in fabric, ceramics and wood. CuidATIVA nursing team actively participates in the reception, which also offers the projects of Thrift and "Tea Bar".

m. Therapeutic Workshop: Interdisciplinary social action based on themes of strategic interest to improve the Quality of Life in Palliative Care. A welcoming and sharing space for talk about the pain, problems and potential of people and the community. An affective and dialog space, open to knowledge from different cultures, focused on exchanges in multiple dimensions (ethical, scientific, cognitive, spiritual, philosophical, etc.) and the tolerant and respectful construction of knowledge.

n. Acupuncture and Auriculotherapy: Chinese techniques aimed mainly at relieving physical and emotional symptoms, such as chronic pain, anxiety, depression, through needling or auricular approach ("microsystem" that represents the whole organism). 

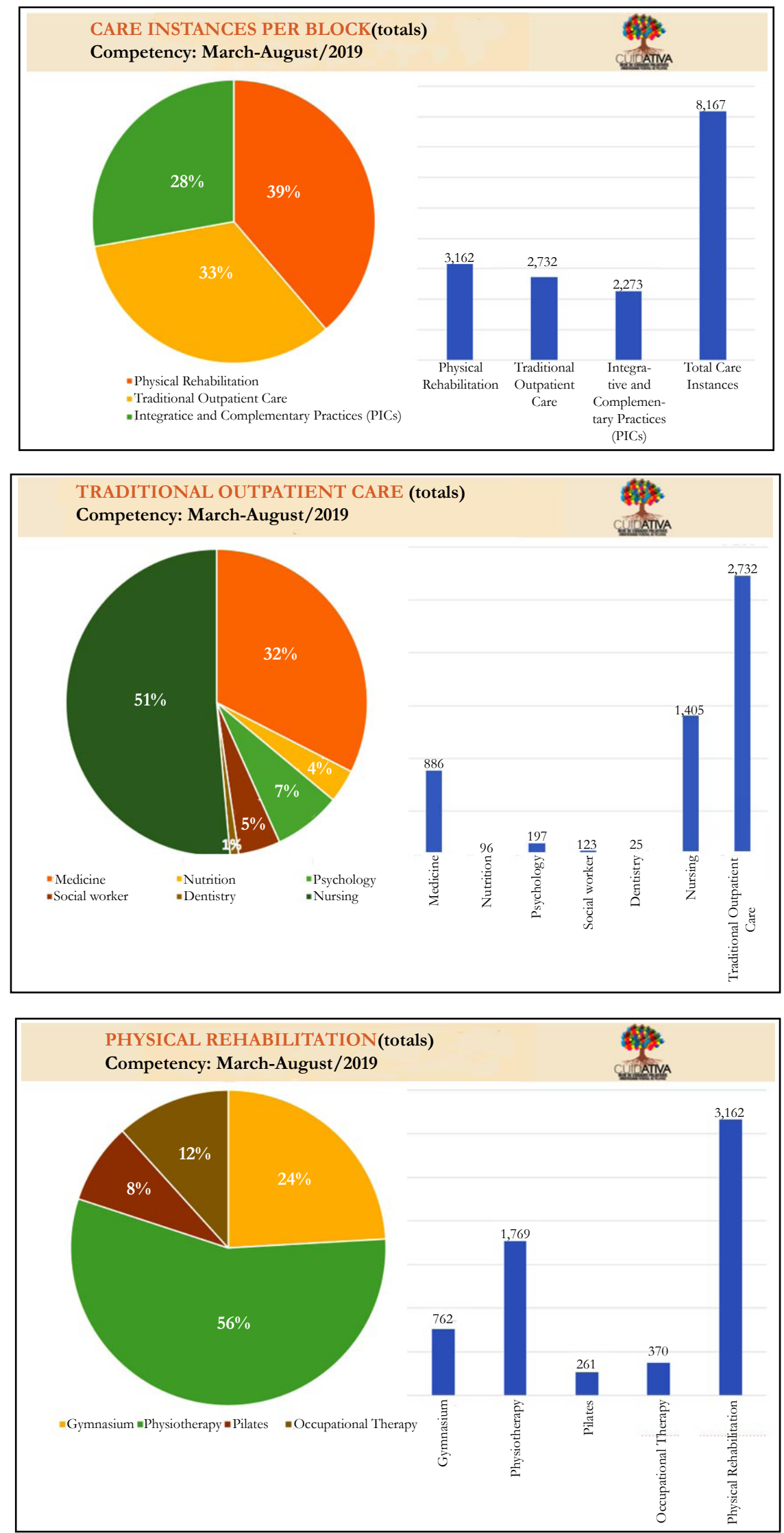
included Curricular Stages in CuidATIVA (Figure 9).

Regarding the Integrative and Complementary Practices, for each PIC, professionals with training in the area apply techniques that lead to the resolution or minimization of problems and sufferings of biopsychosocial and spiritual order of people affected by chronic diseases. Visits can be individual or collective, depending on the PIC or on each patient's need and symptoms burden. The practices may also occur at free and scheduled stations.

Systematically, the professionals and students meet to discuss complex cases for the development of Singular Therapeutic Projects (Figure 10) and for problem solving in the context of expanded clinic in the biweekly interdisciplinary group. Respect for different points of view translate into a favorable environment for the exchange of different professions knowledge, thus ensuring compliance with the effective Palliative Care guidelines for all actors involved.

In addition to the PICs and activities mentioned above, multiprofessional care is provided in the Zeroing Total Pain Action, in the outpatient area of CuidATIVA, through elective consultations by UFPel professionals, according to the "Workers at the School Hospital/UFPel with employment relationship" table.

The multi-professional team continually interacts to prevent and alleviate physical (pain, mobility), social (social network, family support, benefits, rights), emotional (sadness, depression, anxiety) and spiritual (hopelessness, disenchantment, lack of meaning), enabling patients, family members, caregivers, professionals,

Figure 8. Gymnasium/Functional Rehabilitation. CuidATIVA Collection. Date: 2019.

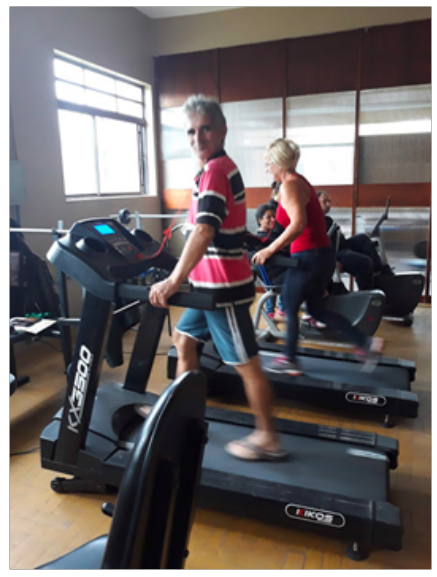

Figure 9. Inauguration of the Physical Rehabilitation area. CuidATIVA Collection. Date: 2018.

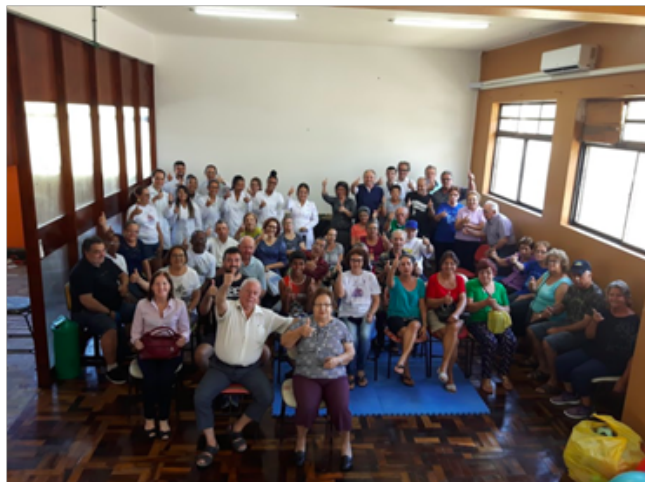

Figure 10. Curriculum activity with students from FAMED/UFPel. CuidATIVA Collection. Date: 2017.

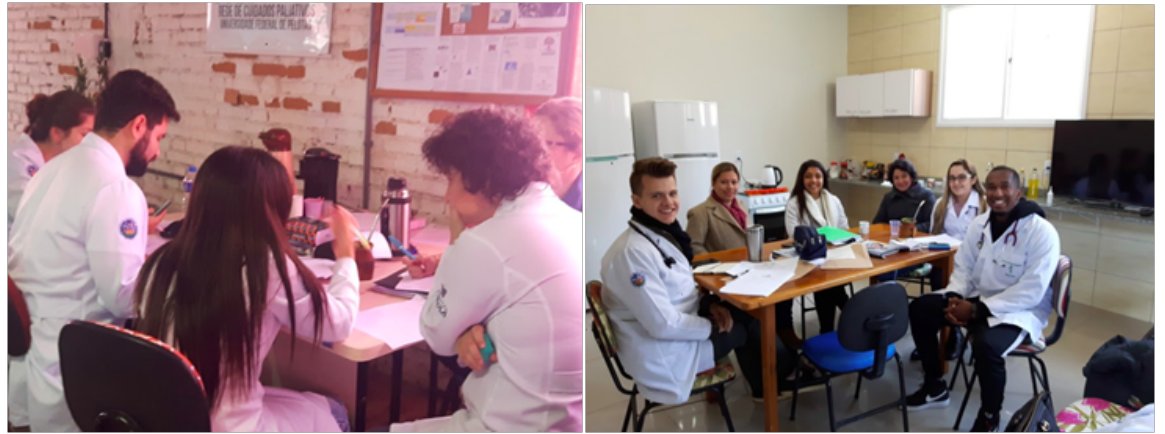


volunteers, teachers and students: rescue of self-esteem; solidarity and more horizontal and harmonious social relations; exchange of experiences for the development of coping strategies in the path of the diseases; improved quality of life; integration of academic and popular knowledge; increased ability to concentrate and self-knowledge; availability of leisure practices and new discoveries in collective environments; meaning of life perception and reduction of fears and anxieties; acquisition of ecologically healthy habits; autonomy and independence; appreciation of the uniqueness of individuals (life stories); identification of individual talents and vocations.

Regarding patients, family members and caregivers, the following is observed: satisfaction with the actions developed; greater adherence to services; higher quality of life; most have a score less than or equal to 2 for the Pain in Analog Visual Scale symptom; improvement of ADL and IADL of patients; reduction of caregiver burden from moderate to severe for mild or no overload; reduction of anxiety and depression symptoms.

Regarding the Multi-professional Teams: increased job satisfaction; reduction of burnout cases; increased integration between different professions; reduction of work overload and absenteeism; improvement of technical qualification in the theme Palliative Care; consolidation of the importance of interdisciplinary care to achieve effective therapeutic results; knowledge exchanges between traditional areas of health care with PICs.

In relation to the Society the following is identified: enhancement of the socialization of Palliative Care and PICs themes in the general community; increased spirit of solidarity, love and affective care of individuals and collectives; stimulating sustainability and creating new perspectives of coexistence; creation of a Joint Support Front for the Regional Center for Palliative Care; installation of a Special Commission for Palliative Care and Approval of the Tall Law, in the Legislative Assembly of Rio Grande do Sul.

CuidATIVA's strength is the solidary involvement of volunteering, the commitment and dedication of professionals, the responsibility and competence of teachers and the motivation and enthusiasm of students, who create opportunities and welcome people.In addition to moments of well-being and leisure, improvements are made, repairs and maintenance of the structures through joint efforts (Figures 11 and 12), festive and commemorative events are organized, academic and integrative activities and the defense of CuidATIVA community rights and dreams.

The care notion developed throughout the process of CuidATIVA presupposes the political mobilization of the community, humanized formation and solidarity actions in the network, which allow experiencing other modes of coexistence, extrapolating selfishness and individualism, combining the scholarly and

Figure 11. Joint Effort for cleaning and external beautification. CuidATIVA Collection. Date: 2018.

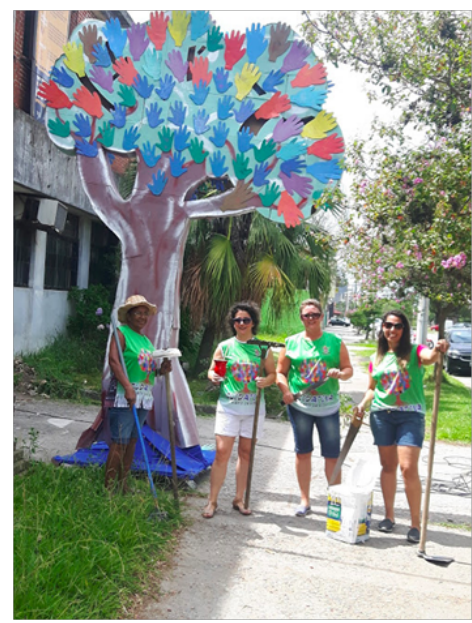

Figure 12. Improvements made by volunteers. CuidATIVA Collection. Date: 2018.

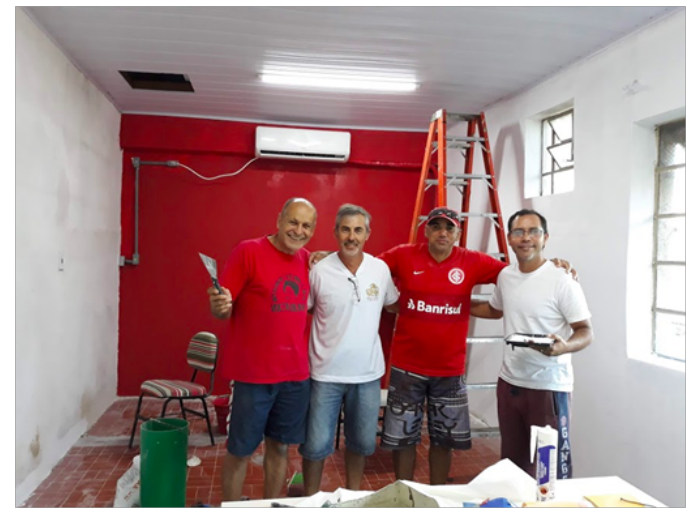


the popular and welcoming the diversity that emanates from knowledge arising from the confluence of different social classes, ethnic and cultural backgrounds, political parties, age groups, religions, gender and sexual options, etc.

CuidATIVA is constituted as we move beyond the territories and areas of knowledge in which we exercise dominion, giving up safe places and dialoguing with other areas and knowledge. This creates possibilities for building a concept of Palliative Care in constant elaboration and re-elaboration, which is not intended to be a model, but rather a reference to stimulate reflection and debate. It is a willingness to deal with everyday problems and to form a care network capable of meeting people's real needs, creating a unique conception of Palliative Care.

The studies developed from the process of implementation of CuidATIVA were presented as possible alternatives to develop motor skills, cognitive, intuitive, relational, sensitive, creative, spiritual, imaginative to improve the quality of life. The training processes are, in this sense, the manifestation of what is happening in the lived world, as events are processed, where theory influences practice and vice versa, in a plot that involves the meaning, the said, the reflected, the dreamed, the seen, the unspeakable, in which the verb to think is conjugated in the eternal gerund, in a movement in permanent deconstruction and inventive creation.

\section{References}

[1]. Amaral AL, Gentini AG, Amaral RA. Group as a device: the ecosystemic microintervention in training processes in environmental education. Education and Research. 2018; 44: 1-8.

[2]. Baremblitt GF. Compendium of institutional analysis and other currents: theory and practice.6th ed. Rio de Janeiro: Rosa dos Times; 1996.

[3]. Ministry of Health. Thematic glossary: integrative and complementary health practices. Executive Secretariat, Health Care Secretariat, Brasilia .2018 [Accessed 22 Nov 2019]. Available from: https://portalarquivos2. saude.gov.br/images/pdf/2018/marco/12/glossario-tematico.pdf

[4]. CASTELLS, Manuel. The Information Age: Economy, Society and Culture Vol 2-The Power of Identity. São Paulo, Ed. Paz e Terra.1999; 1 (2).

[5]. Guattari F, Deleuze G. A thousand plateaus: capitalism and schizophrenia. Publisher 34; 1995.

[6]. Deleuze G. Conversations. Publisher 34; 1992.
[7]. Deleuze G. Difference and repetition (rev.). Rio de Janeiro: Graal. (Original work published in 1968). 2006.

[8]. Guattari F, Deleuze G. What is philosophy. Rio de Janeiro: Publisher. 1992; 34.

[9]. Guattari F. The Three Ecologies. Ed. Campinas \& Papirus, São Paulo. 1990.

[10]. Ferrara LD. Peripheral look: information, language, environmental perception. Edusp; 1993.

[11]. Kosik K. Dialectic of concrete, Peace and Earth. Rio de Janeiro. 1976;2:202.

[12]. Ministry of Health.Unified Health System (SUS): structure, principles and how it works.Dec 2019.

[13]. Morin E. Introduction to complex knowledge. $4^{\text {th }}$ ed. Porto Alegre: Publisher Moridional Ltda; 2011.

[14]. Santos BS. A Discourse on Science. $5^{\text {th }}$ ed. Cortez,São Paulo.2008.

[15]. WHO (World Health Organization) 2002.

[16]. Pinto JM. Jürgen Habermas' theory of communicative action: basic concepts and possibilities of application to school administration. Paidéia (Ribeirão Preto). 1995 Aug; 8(9):77-96.

[17]. Lubenow JA. The sphere category publishes in Jurgen Habermas.2007.

[18]. Morin E. The seven knowledge necessary for the education of the future. Cortez Editor. 2014 Nov 7;1-12.

[19]. CuidATIVA - Regional Center for Palliative Care - School of Medicine. [Acessed 2020 Jan 27]. Available from: https://wp.ufpel.edu.br/cuidativa/

[20]. Fripp JC, Facchini LA, Silva SM. Characterizing a home and palliative care program in the Municipality of Pelotas, State of Rio Grande do Sul, Brazil: a contribution to full attention to cancer patients at the National Unified Health System. Epidemiology and Health Service. Jan-mar 2012, 21(1):6978. http://dx.doi.org/10.5123/S1679-49742012000100007

[21]. Fripp, JC. Survival and Quality of Life of Individuals with Cancer Registered in Services of High Complexity in the Municipality of Pelotas-RS. Thesis (doctorate) - Federal University of Pelotas, Post-Graduation Program in Nursing. Pelotas, RS, 2015.[Acessed 2020 Jan 27]. Available from: https://wp.ufpel.edu.br/pgenfermagem/files/2016/02/TESE-Julieta-MariaCarriconde-Fripp.pdf

[22]. Lubenow JA. Jürgen Habermas: the category of "public sphere". Thesis (doctorate) - State University of Campinas, Institute of Philosophy and $\mathrm{Hu}-$ man Sciences. Campinas, SP, 2007. [Acessed 2020 Jan 27]. Available from: https://web.archive.org/web/20120514175956/http://criticanarede.com/ docs/habermas.pdf\#

[23]. Morin E. The seven knowledge necessary for the education of the future. 2th ed. Cortez, São Paulo. UNESCO, Brasília/DF, 2011.

[24]. Palliative care services quality management. [Acessed 2020 Jan 27]. Available from: http://bvsms.saude.gov.br/bvs/publicacoes/inca/gestao_da_qualidade.pdf

[25]. Pinto JMR. Paidéia (Ribeirão Preto), Jürgen Habermas' theory of communicative action: basic concepts and possibilities of application to school administration, Feb./Aug. 1995:http://dx.doi.org/10.1590/S0103$863 \times 1995000100007$

[26]. World Health Organization (WHO) - Palliative Care. [Acessed 2020 Jan 27]. Available from: https://www.who.int/news-room/fact-sheets/detail/ palliative-care 